\title{
Comorbidity Management in Black Women Diagnosed with Breast Cancer: the Role of Primary Care in Shared Care
}

\author{
Michelle Doose, PhD, MPH ${ }^{1,2,3}$ (D), Michael B. Steinberg, MD, MPH', \\ Cathleen Y. Xing, PhD, MPH ${ }^{2}$, Yong Lin, PhD ${ }^{2}$, Joel C. Cantor, ScD 5,6 , \\ Chi-Chen Hong, $P h D^{7,8}$, Kitaw Demissie, MD, PhD ${ }^{9}$, Elisa V. Bandera, MD, $P h D^{2,3}$, and \\ Jennifer Tsui, PhD, MPH ${ }^{10}$
}

\begin{abstract}
'Healthcare Delivery Research Program, Division of Cancer Control and Population Sciences, National Cancer Institute, 9609 Medical Center Drive, 3E502, Rockville, MD, USA; ${ }^{2}$ Rutgers School of Public Health, Piscataway, NJ, USA; ${ }^{3}$ Rutgers Cancer Institute of New Jersey, New Brunswick, NJ, USA; ${ }^{4}$ Rutgers Robert Wood Johnson Medical School, New Brunswick, NJ, USA; ${ }^{5}$ Rutgers Center for State Health Policy, New Brunswick, NJ, USA; ${ }^{6}$ Rutgers Edward J. Bloustein School of Planning and Public Policy, New Brunswick, NJ, USA; ${ }^{7}$ University at Buffalo, Buffalo, NY, USA; ${ }^{2}$ Roswell Park

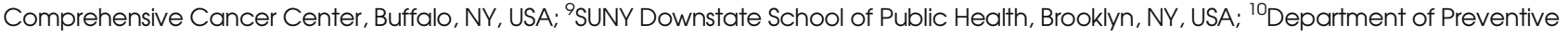
Medicine, Keck School of Medicine, University of Southern California, Los Angeles, CA, USA.
\end{abstract}

\begin{abstract}
BACKGROUND: Black women are more likely to have comorbidity at breast cancer diagnosis compared with White women, which may account for half of the BlackWhite survivor disparity. Comprehensive disease management requires a coordinated team of healthcare professionals including primary care practitioners, but few studies have examined shared care in the management of comorbidities during cancer care, especially among racial/ethnic minorities.
\end{abstract}

OBJECTIVE: To examine whether the type of medical team composition is associated with optimal clinical care management of comorbidities.

DESIGN: We used the Women's Circle of Health Follow-up Study, a population-based cohort of Black women diagnosed with breast cancer. The likelihood of receiving optimal comorbidity management after breast cancer diagnosis was compared by type of medical team composition (shared care versus cancer specialists only) using binomial regression.

PARTICIPANTS: Black women with a co-diagnosis of diabetes and/or hypertension at breast cancer diagnosis between 2012 and $2016(N=274)$.

MAIN MEASURES: Outcome-optimal clinical care management of diabetes (i.e., A1C test, LDL-C test, and medical attention for nephropathy) and hypertension (i.e., lipid screening and prescription for hypertension medication). Main predictor-shared care, whether the patient received care from both a cancer specialist and a primary care provider and/or a medical specialist within the 12 months following a breast cancer diagnosis.

KEY RESULTS: Primary care providers were the main providers involved in managing comorbidities and 90\% of patients received shared care during breast cancer care. Only 54\% had optimal comorbidity management. Patients with shared care were five times (aRR: 4.62;

Prior Presentations Information presented in this manuscript was presented at the American Association for Cancer Research-The Science of Cancer Health Disparities in Racial/Ethnic Minorities and the Medically Underserved, San Francisco, CA, September 20-23, 2019.

Received March 25, 2020

Accepted September 10, 2020

Published online September 24, 2020
95\% CI: $1.66,12.84)$ more likely to have optimal comorbidity management compared with patients who only saw cancer specialists.

CONCLUSIONS: Suboptimal management of comorbidities during breast cancer care exists for Black women. However, our findings suggest that shared care is more beneficial at achieving optimal clinical care management for diabetes and hypertension than cancer specialists alone.

KEY WORDS: shared care; breast cancer; comorbidity; patient care; practice guideline.

J Gen Intern Med 36(1):138-46

DOI: $10.1007 / \mathrm{s} 11606-020-06234-\mathrm{x}$

(C) Society of General Internal Medicine (This is a U.S. government work and not under copyright protection in the U.S.; foreign copyright protection may apply) 2020

\section{INTRODUCTION}

In 2020, an estimated 276,480 women will be diagnosed with breast cancer, of which $32 \%$ will have comorbidity at diagnosis. ${ }^{1-3}$ Two of the most common comorbidities that affect this population are type 2 diabetes mellitus (affecting 16-20\%) and hypertension $(32 \%){ }^{4}$ Women with a comorbidity at breast cancer diagnosis are more likely to be Black. ${ }^{5-7}$ This may be due to the fact that the prevalence of diabetes and hypertension in the US population is higher among Black women (13\% and $40 \%$ ) compared with non-Hispanic White women (7\% and $26 \%) .{ }^{8,9}$ Having a comorbidity can limit breast cancer treatment options and breast cancer treatment can exacerbate underlying health conditions. ${ }^{10,11}$ For example, having diabetes during breast cancer treatment increases the risk for infection, hospitalization, poor physical function, and mortality. ${ }^{12-15}$ It is critical to manage and control patients' comorbidities because breast cancer survivors are more likely to die from competing causes than from breast cancer. ${ }^{4,16-19}$

Co-managing both breast cancer and comorbidities requires a comprehensive, coordinated team of healthcare professionals, with the patient at the center of treatment decisions. This team 
of two or more healthcare professionals jointly participating in patient's care is defined as shared care as well as team-based care, multidisciplinary team care, and collaborative care. ${ }^{20-24}$ The team may include cancer specialists, primary care providers, and other medical subspecialists that share the patient's care. Two studies found that 30-50\% of breast cancer patients had shared care during cancer care. ${ }^{25,}{ }^{26}$ Limited studies of shared care have demonstrated improved symptom management, treatment initiation, adherence, and quality cancer care. ${ }^{21,23,27,28}$

The importance of shared care is recognized by national cancer organizations as a key component for the delivery of high-quality care. The Ensuring Quality Cancer Care report (1999) highlighted the important role of multidisciplinary teams in cancer care. ${ }^{29}$ The Lost in Transition report (2006) promoted shared care for cancer survivorship. ${ }^{30}$ The Commission on Cancer accredits cancer programs on the provision of "coordination of care among many medical disciplines. ${ }^{31}$ " The American Society of Clinical Oncology also states that team-based care is a "cornerstone of quality care." ${ }^{32}$ Despite the focus on the importance of shared care, there is a lack of empirical studies that assess the quality of comorbid care by medical team composition.

Given that diabetes and hypertension are two common comorbidities that affect breast cancer population and Black women, contribute to the Black-White breast cancer survival disparity, and have well-established clinical guidelines, we sought to examine the types of medical providers involved in diabetes and hypertension clinical care management among cancer patients and whether medical team composition was associated with receipt of optimal clinical care management. We hypothesized that patients who have shared care after breast cancer diagnosis are more likely to receive optimal clinical care management for diabetes and hypertension compared with patients who only see cancer specialists, after controlling for patient-level factors.

\section{MATERIALS AND METHODS}

\section{Data Source and Study Population}

The Women's Circle of Health Follow-up Study (WCHFS) is an ongoing, longitudinal study of self-identified African American/Black breast cancer survivors (referred to hereafter as Black) in ten counties in New Jersey. The study has been described in detail elsewhere. ${ }^{33}$ In brief, eligible patients are first identified through the New Jersey State Cancer Registry using rapid case ascertainment methodology (i.e., cases identified via pathology report within 2 months of cancer diagnosis). ${ }^{34}$ Once recruited, a WCHFS research member conducts an in-person interview with each participant at approximately 9-12 months after her cancer diagnosis. At this interview, written informed consent, medical and pharmacy records releases, and contact information for all medical providers are collected. Participants are asked to identify all providers involved in breast cancer care and comorbid care in the
12 months prior to the breast cancer diagnosis through the day she consents for medical release. Additionally, medical and sociodemographic questionnaires are administered, and anthropometric measurements are collected during this interview. The medical records are then requested from surgical, medical, and radiation oncologists; primary care; subspecialists; and hospitals where surgeries and treatments were performed. All medical records are then abstracted and entered into a database by trained abstractors. Information abstracted include breast cancer diagnosis workup, breast cancer treatments recommended and received, comorbidity type and their management, and vital status. ${ }^{33}$

For this analysis, breast cancer patients had a medical documentation of diabetes or hypertension at least 12 months prior to breast cancer diagnosis and had their medical records abstracted for breast cancer information through July 2018. These women were diagnosed with breast cancer between 2012 and 2016. Inclusion criteria are as follows: primary, histologically confirmed non-invasive ductal carcinoma in situ (DCIS) or invasive breast cancer; self-identified as African American/Black; 20-75 years old; and able to understand and read English. Exclusion criteria are the following: metastatic breast cancer, death within 12 months of cancer diagnosis; or any provider refused to send medical records. This study was approved by the institutional review boards of all participating institutions and written informed consent was obtained from all study participants.

\section{Measures}

Outcome Measure-Optimal Management. Although there are no specific guidelines for the management of diabetes and hypertension during breast cancer, there are evidence-based clinical practice guidelines for the management of diabetes and hypertension for the general non-cancer population. Diabetes clinical care management measures selected for this analysis included: glycosylated hemoglobin (A1c) test, lowdensity lipoprotein-cholesterol (LDL-C) test, and medical attention for nephropathy (i.e., urine albumin/microalbuminuria test, documentation of treatment for nephropathy, or prescription for angiotensin-converting enzyme (ACE) inhibitor or angiotensin receptor blocker (ARB) therapy). ${ }^{35-42}$ Hypertension clinical care management measures selected for this analysis included: lipid screening and prescription for hypertension medication - thiazide-type diuretic, calcium channel blocker, ACE inhibitor, ARB therapy, a vasodilator (e.g., hydralazine), and others (e.g., aliskiren, minoxidil). ${ }^{36,43-47}$ Two abstractors collected additional information from medical and pharmacy records: date of visit or test/prescription ordered, name of ordering provider, facility name, and type/ result of test or medication ordered. We then constructed a binary outcome measure for receipt of optimal clinical care management (referred to hereafter as optimal management) using the All-or-None measurement approach. If the patient's provider(s) ordered all clinical care management measures (i.e., 3 measures for diabetes and 2 measures for hypertension) 
within the 12 months following the date of diagnosis (i.e., date of biopsy), then the patient was categorized as receiving optimal management (value $=1$ ). When at least one measure was not ordered, then the patient was categorized as not receiving optimal management (reference; value $=0$ ). This All-or-None measurement approach has been used in other studies to examine care quality and for quality monitoring by health plans. ${ }^{48}$

Main Predictor-Shared Care. Types of health professionals seen included cancer specialists (i.e., medical, radiation, and surgical oncologists), primary care providers (i.e., internal medicine, family medicine), and medical specialists related to diabetes or hypertension (i.e., endocrinologist, cardiologist, and nephrologist). In this study, if a patient had a visit with any cancer specialist, primary care provider, or medical specialist, then that provider was considered involved in care. We then dichotomized the types of medical team composition into two categories: (1) shared care, where the patient received care from both a cancer specialist and a primary care provider and/or medical subspecialists within the 12 months following a breast cancer diagnosis and (2) cancer specialists only, where the patient received care from only cancer specialists.

Covariates. We used the Taplin's Quality of Cancer Care Model, Anderson's Behavioral Model of Health Services Utilization, and Donabedian Quality-of-Care Model to inform the analytic framework. ${ }^{49-52}$ Covariates selected for this analysis included disease severity of the cancer and comorbidity and health insurance status, which are known confounders for disease management, as well as age and comorbidity type. Age and health insurance at diagnosis, American Joint Committee on Cancer (AJCC) cancer stage, and comorbidities including type, severity, and year of onset were abstracted from medical records. When health insurance status at diagnosis could not be ascertained from medical records, we used the health insurance status 1 year prior to diagnosis collected from the home interview. Diabetes and hypertension-related disease severity was abstracted from medical records, including any eye, foot, diabetic heart or kidney disease, or congestive heart failure. Then, we constructed a binary variable: organ damage versus none. Missing data were coded as unknown.

\section{Statistical Analysis}

Descriptive statistics were generated for patient and provider characteristics by comorbidity. Comorbidities included patients with diabetes and hypertension $(n=102$; including eight patients with diabetes only) and patients with hypertension only $(n=172)$. Each of diabetes and hypertension clinical care management measure was reported by type of provider who ordered the first test, days from cancer diagnosis of when the test was ordered, and as an All-or-None measure of optimal management. The likelihood of receiving optimal management after a breast cancer diagnosis was compared by medical
Table 1 Sociodemographics and Clinical Characteristics of Black Women with Diabetes and/or Hypertension in the Women's Circle of Health Follow-up Study, Diagnosed with Breast Cancer 2012$2016(N=274)$

\begin{tabular}{|c|c|c|c|}
\hline & $\begin{array}{l}\text { Patients with } \\
\text { diabetes and } \\
\text { hypertension }{ }^{\dagger} \\
(n=102)\end{array}$ & $\begin{array}{l}\text { Patients with } \\
\text { hypertension } \\
\text { only }(n=172)\end{array}$ & $\begin{array}{l}\text { Total } \\
\text { population } \\
(N=274)\end{array}$ \\
\hline & No. $(\%)$ & No. $(\%)$ & No. $(\%)$ \\
\hline \multicolumn{4}{|c|}{ Sociodemographics } \\
\hline $\begin{array}{l}\text { Age at } \\
\text { diagnosis, } \\
\text { years (mean } \pm \\
\text { SD) }\end{array}$ & $60.9 \pm 8.2$ & $57.0 \pm 9.1$ & $58.5 \pm 9.0$ \\
\hline $\begin{array}{l}<55 \\
55-64 \\
65-75\end{array}$ & $\begin{array}{l}24(23.5) \\
36(35.3) \\
42(41.2)\end{array}$ & $\begin{array}{l}72(41.9) \\
58(33.7) \\
42(24.4)\end{array}$ & $\begin{array}{l}96(35.0) \\
94(34.3) \\
84(30.7)\end{array}$ \\
\hline \multicolumn{4}{|l|}{ Marital status } \\
\hline Married & $34(33.3)$ & $63(36.6)$ & $97(35.4)$ \\
\hline $\begin{array}{l}\text { Not married } \\
\text { Education }\end{array}$ & $68(66.7)$ & $109(63.4)$ & $177(64.6)$ \\
\hline $\begin{array}{l}\leq \text { High } \\
\text { school }\end{array}$ & $44(43.1)$ & $69(40.1)$ & $113(41.2)$ \\
\hline $\begin{array}{l}>\text { High } \\
\text { school }\end{array}$ & $58(56.9)$ & $103(59.9)$ & $161(58.8)$ \\
\hline \multicolumn{4}{|c|}{ Annual household income } \\
\hline $\begin{array}{l}\text { Less than } \\
\$ 70,000 / \\
\text { unknown }\end{array}$ & $83(81.4)$ & $118(68.6)$ & $136(49.6)$ \\
\hline $\begin{array}{l}\$ 70,000 \text { or } \\
\text { more }\end{array}$ & 19 (18.6) & $54(31.4)$ & $73(26.6)$ \\
\hline \multicolumn{4}{|c|}{ Health insurance at breast diagnosis } \\
\hline Medicaid & $23(22.5)$ & $25(14.5)$ & $48(17.5)$ \\
\hline Medicare & $39(38.2)$ & $38(22.1)$ & $77(28.1)$ \\
\hline Private & $38(37.3)$ & $97(56.4)$ & $135(49.3)$ \\
\hline None/ & $2(2.0)$ & $12(7.0)$ & $14(5.1)$ \\
\hline \multicolumn{4}{|c|}{$\begin{array}{l}\text { charity/ } \\
\text { unknown }\end{array}$} \\
\hline \multirow{2}{*}{\multicolumn{4}{|c|}{$\begin{array}{l}\text { Tumor and comorbid characteristics } \\
\text { AJCC stage }\end{array}$}} \\
\hline & & & \\
\hline 0 (DCIS) & $27(26.5)$ & $41(23.8)$ & $68(24.8)$ \\
\hline I & $34(33.3)$ & $53(30.8)$ & $87(31.8)$ \\
\hline II & $32(31.4)$ & $60(34.9)$ & $92(33.6)$ \\
\hline III & $9(8.8)$ & $18(10.5)$ & $27(9.9)$ \\
\hline $\begin{array}{l}\text { Duration of } \\
\text { diabetes, years } \\
(\text { mean } \pm \text { SD) }\end{array}$ & $11.4 \pm 8.7$ & - & - \\
\hline $\begin{array}{l}\text { Duration of } \\
\text { hypertension, } \\
\text { years (mean } \pm \\
\text { SD) }\end{array}$ & $16.1 \pm 12.7$ & $13.0 \pm 11.8$ & $14.1 \pm 12.2$ \\
\hline Disease severi & \\
\hline $\begin{array}{l}\text { No organ } \\
\text { damage }\end{array}$ & $70(68.6)$ & $170(98.8)$ & $240(87.6)$ \\
\hline $\begin{array}{l}\text { Organ } \\
\text { damage }\end{array}$ & $32(31.4)$ & $2(1.2)$ & $34(12.4)$ \\
\hline \multicolumn{4}{|c|}{ Count of comorbidity* } \\
\hline 1 & $4(3.9)$ & $96(55.8)$ & $100(36.5)$ \\
\hline 2 & $40(39.2)$ & $51(29.7)$ & $91(33.2)$ \\
\hline$\geq 3$ & $58(56.9)$ & $25(14.5)$ & $83(30.3)$ \\
\hline $\begin{array}{l}\text { Body mass } \\
\text { index, } \mathrm{kg} / \mathrm{m}^{2} \\
(\text { mean } \pm \mathrm{SD})\end{array}$ & $34.0 \pm 6.9$ & $32.8 \pm 6.9$ & $33.3 \pm 6.9$ \\
\hline
\end{tabular}

SD, standard deviation; AJCC, American Joint Committee on Cancer *Comorbidities presented at or before breast cancer diagnosis include: HIV/AIDS, arthritis, asthma, congestive heart failure, diabetes, chronic liver disease, ascites, hepatic encephalopathy, hypertension, myocardial infarction, angina, premature ventricular contractions, chronic renal disease, osteoporosis, chronic obstructive pulmonary disease (count excludes breast cancer diagnosis)

FIncludes 8 patients with diabetes only 
Table 2 Provider Characteristics Among Black Women with Diabetes and/or Hypertension in the Women's Circle of Health Follow-up Study, Diagnosed with Breast Cancer 2012-2016 $(N=274)$

\begin{tabular}{|c|c|c|c|}
\hline & $\begin{array}{l}\text { Patients with diabetes and } \\
\text { hypertension }(n=102)\end{array}$ & $\begin{array}{l}\text { Patients with hypertension only } \\
(n=172)\end{array}$ & $\begin{array}{l}\text { Total Population } \\
(N=274)\end{array}$ \\
\hline & No. $(\%)$ & No. $(\%)$ & No. $(\%)$ \\
\hline \multicolumn{4}{|l|}{ Before breast cancer diagnosis } \\
\hline \multicolumn{4}{|l|}{ Medical provider seen* } \\
\hline Primary care provider & $87(85.3)$ & $140(81.4)$ & $227(82.9)$ \\
\hline Endocrinologist & $16(15.7)$ & - & \\
\hline Cardiologist & $23(22.5)$ & $22(12.8)$ & $45(16.4)$ \\
\hline Nephrologist & $3(2.9)$ & $6(3.5)$ & $9(3.3)$ \\
\hline \multicolumn{4}{|l|}{ Median days to last provider visit } \\
\hline Primary care provider & 42 & 39 & 40 \\
\hline Endocrinologist & 63 & - & - \\
\hline Cardiologist & 112 & 111 & 112 \\
\hline Nephrologist & 116 & 33 & 47 \\
\hline \multicolumn{4}{|l|}{ Number of providers seen ${ }^{\dagger}$} \\
\hline 0 & $6(5.9)$ & $27(15.7)$ & $33(12.0)$ \\
\hline 1 & $53(52.0)$ & $123(71.5)$ & $176(64.2)$ \\
\hline 2 or more & $43(42.2)$ & $22(12.8)$ & $65(23.7)$ \\
\hline \multicolumn{4}{|l|}{ Medical team composition } \\
\hline None & $8(7.8)$ & $27(15.7)$ & $35(12.8)$ \\
\hline Primary care provider only & $57(55.9)$ & $118(68.6)$ & $175(63.9)$ \\
\hline Medical specialist(s) only & $7(6.9)$ & $5(2.9)$ & $12(4.4)$ \\
\hline Primary care provider and medical & $30(29.4)$ & $22(12.8)$ & $52(19.0)$ \\
\hline specialist(s) & & & \\
\hline \multicolumn{4}{|l|}{ After breast cancer diagnosis } \\
\hline \multicolumn{4}{|l|}{ Medical provider seen* } \\
\hline Breast surgeon & $102(100.0)$ & $172(100.0)$ & $274(100.0)$ \\
\hline Medical oncologist & $95(93.1)$ & $163(94.8)$ & $258(94.2)$ \\
\hline Radiation oncologist & $75(73.5)$ & $135(78.5)$ & $210(76.6)$ \\
\hline Primary care provider & $88(86.3)$ & $148(86.1)$ & $236(86.1)$ \\
\hline Endocrinologist & $22(21.6)$ & - & - \\
\hline Cardiologist & $26(25.5)$ & $27(15.7)$ & $53(19.3)$ \\
\hline Nephrologist & $9(8.8)$ & $5(2.9)$ & $14(5.1)$ \\
\hline \multicolumn{4}{|l|}{ Median days to first provider visit } \\
\hline Primary care provider & 38 & 44 & 42 \\
\hline Endocrinologist & 58 & - & - \\
\hline Cardiologist & 52 & 151 & 63 \\
\hline Nephrologist & 149 & 176 & 163 \\
\hline \multicolumn{4}{|l|}{ Number of providers seen ${ }^{\dagger}$} \\
\hline 1 & $0(0.0)$ & $0(0.0)$ & $0(0.0)$ \\
\hline 2 & $4(3.9)$ & $12(7.0)$ & $16(5.8)$ \\
\hline 3 & $16(15.7)$ & $40(23.3)$ & $56(20.4)$ \\
\hline 4 & $42(41.2)$ & 9655.8() & $138(50.4)$ \\
\hline \multirow{2}{*}{\multicolumn{4}{|c|}{$\begin{array}{l}5 \text { or more } \\
\text { Medical team composition }\end{array}$}} \\
\hline & & & \\
\hline Cancer specialists only & $5(4.9)$ & $22(12.8)$ & $27(9.9)$ \\
\hline Primary care provider and cancer & $51(50.0)$ & $120(69.8)$ & $171(62.4)$ \\
\hline specialists & & & \\
\hline Medical and cancer specialists & $9(8.8)$ & $2(1.2)$ & $11(4.0)$ \\
\hline $\begin{array}{l}\text { Primary care provider, medical, and } \\
\text { cancer specialists }\end{array}$ & $37(36.3)$ & $28(16.3)$ & $65(23.7)$ \\
\hline
\end{tabular}

*At least one visit with a provider within 12 months from date of diagnosis

† Number of providers includes primary care provider, endocrinologist, cardiologist, and nephrologist, and after cancer diagnosis includes medical, radiation, and surgical oncologists

fCancer specialist includes medical, radiation, and surgical oncologist. Medical specialist includes endocrinologist, cardiologist, and nephrologist

team composition (shared care versus cancer specialists only) using unadjusted and adjusted binomial regression models. The adjusted model controlled for age, health insurance, cancer stage, and comorbidity type and severity. When the binomial regression failed to converge, the modified Poisson regression was used to approximate a binomial regression for all models. ${ }^{53}$ Unadjusted and adjusted relative risks (aRR) and 95\% confidence intervals (CIs) were reported. $P$ values less than the 0.05 significance level (two-sided) were considered statistically significant. All analyses were performed using SAS version 9.4 (SAS Institute, Cary, NC).

\section{RESULTS}

Among this study population of 274 Black breast cancer survivors with diabetes and/or hypertension, the mean age at breast cancer diagnosis was 59 years, half were privately insured, and three-fourths had invasive breast cancer (Table 1). Among patients with diabetes, the mean duration of diabetes and hypertension was 11 years and 16 years, and $31 \%$ had diabetes-related organ damage. Among patients with hypertension only, the mean duration of hypertension was 13 years, and 99\% did not have hypertension-related organ damage. Most patients saw a primary care provider at least 


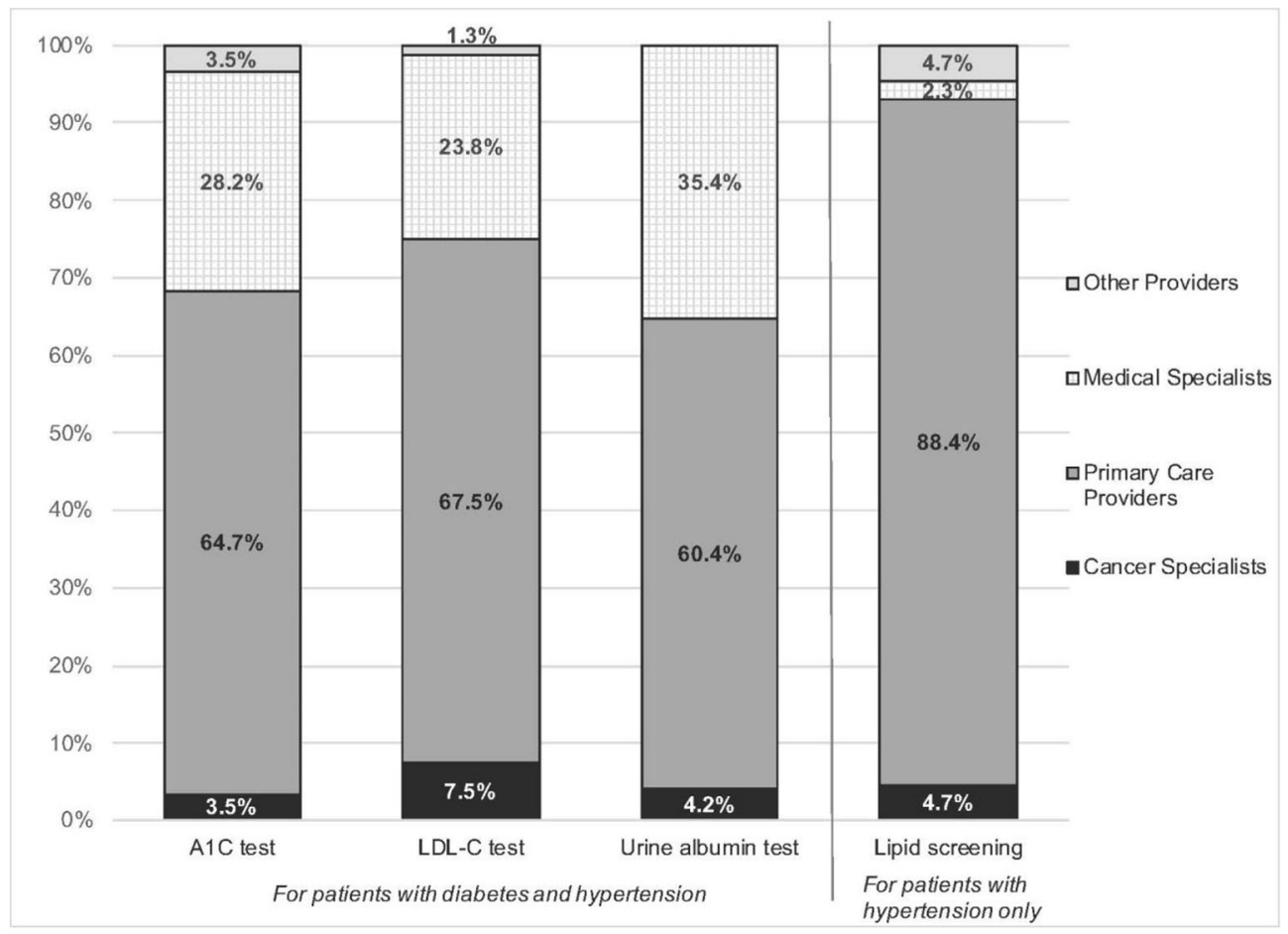

Other providers include physicians seen in the emergency department and inpatient hospital, neurologist, and unknown providers

Figure 1 Medical providers who managed diabetes and hypertension clinical care

once in the 12 months before and after cancer diagnosis (83\% and $86 \%$ ) while only $20 \%$ saw a medical specialist (Table 2 ). The median days from diagnosis to the first primary care visit were 42 days. The majority of patients (90\%) had shared care

Table 3 Regression Models of the Association Between Medical Team Composition and Optimal Management of Diabetes and/or Hypertension $(\mathbf{N}=\mathbf{2 7 4})$

\begin{tabular}{|c|c|c|}
\hline & \multicolumn{2}{|c|}{ Optimal management } \\
\hline & \multirow{2}{*}{$\frac{\text { Unadjusted }}{\text { RR }(95 \% \mathrm{CI})}$} & \multirow{2}{*}{$\frac{\text { Adjusted }}{\text { RR }(95 \% \text { CI })}$} \\
\hline & & \\
\hline \multicolumn{3}{|l|}{ Medical team composition } \\
\hline Cancer specialists only & 1.00 (referent) & 1.00 (referent) \\
\hline Shared care & $5.24(1.80-15.33)$ & $4.62(1.66-12.84)$ \\
\hline \multicolumn{3}{|l|}{ Age at diagnosis, years } \\
\hline $65-75$ & 1.00 (referent) & 1.00 (referent) \\
\hline $55-64$ & $0.88(0.69-1.11)$ & $0.94(0.74-1.19)$ \\
\hline$<55$ & $0.65(0.49-0.86)$ & $0.75(0.56-1.00)$ \\
\hline \multicolumn{3}{|l|}{ Health insurance at diagnosis } \\
\hline Private & 1.00 (referent) & 1.00 (referent) \\
\hline Medicaid & $1.16(0.86-1.55)$ & $1.04(0.79-1.37)$ \\
\hline Medicare & $1.21(0.95-1.55)$ & $0.96(0.75-1.23)$ \\
\hline None/charity/unknown & $0.57(0.24-1.32)$ & $0.64(0.28-1.44)$ \\
\hline \multicolumn{3}{|l|}{ AJCC stage } \\
\hline 0 (DCIS) & 1.00 (referent) & 1.00 (referent) \\
\hline I & $0.99(0.74-1.31)$ & $1.04(0.80-1.36)$ \\
\hline II-III & $0.92(0.70-1.21)$ & $1.00(0.78-1.28)$ \\
\hline \multicolumn{3}{|l|}{ Comorbidity type } \\
\hline Hypertension only & 1.00 (referent) & 1.00 (referent) \\
\hline Diabetes and hypertension & $1.71(1.38-2.11)$ & $1.61(1.29-2.00)$ \\
\hline \multicolumn{3}{|l|}{ Disease severity } \\
\hline No organ damage & 1.00 (referent) & 1.00 (referent) \\
\hline Organ damage & $1.18(0.88-1.57)$ & $0.80(0.60-1.06)$ \\
\hline
\end{tabular}

AJCC, American Joint Committee on Cancer with the most common medical team composition being cancer specialists and primary care providers $(62 \%)$.

Overall, $54 \%$ of this population had optimal comorbidity management. Among patients with diabetes, optimal management was achieved for $73 \%$ including $83 \%$ who had an $\mathrm{HbAlc}$ ordered, $78 \%$ who had an LDL-C test ordered, and 94\% who received medical attention for nephropathy. Among patients with hypertension only, optimal management was achieved for $42 \%$, including 50\% who had a lipid screening ordered and $83 \%$ who received at least one prescription for hypertension medication. Primary care providers were the main medical provider involved in managing the comorbidities during cancer care followed by medical specialists (Fig. 1). For diabetes care, $65 \%$ of the first A1C tests, $68 \%$ of LDL-C tests, and $60 \%$ of urine albumin tests were ordered by a primary care provider. Cancer specialists were mostly involved in ordering the first lipid test. When we examined all tests ordered within the 12 months from diagnosis, the findings did not change.

More than half of patients with shared care had optimal management of diabetes and hypertension (58\%) compared with only $11 \%$ of patients who saw cancer specialists only. Table 3 shows the association between shared care and optimal management after a breast cancer diagnosis. In the adjusted regression model, patients with shared care were almost five times more likely to have optimal management compared with patients who only saw cancer specialists (aRR: 4.62; 95\% CI: 1.66, 12.84), controlling for patients' age and health insurance at diagnosis, AJCC stage, and comorbidity type and severity. 


\section{DISCUSSION}

In our study, $90 \%$ of patients had shared care during breast cancer care (i.e., care provided by cancer specialists, primary care providers, and/or medical specialists within 12 months of cancer diagnosis). This was found to be associated with an increased likelihood of having optimal management for diabetes and hypertension. This is the first study to our knowledge to examine the relationship between shared care and chronic disease management among minority breast cancer patients. This is important given that the Black-White breast cancer survival disparity may be due in large part to the higher prevalence of comorbidities and disparate access to comorbid care and treatment experienced by Black women. ${ }^{4,54}$

Another key finding from this research was the suboptimal management of comorbidities for Black breast cancer survivors. It is concerning that only $54 \%$ of patients had optimal comorbidity management, including only $58 \%$ of patients with shared care. This warrants further exploration of whether competing care demands or the lack of role delineation and communication between providers is leading to poor comorbidity management during cancer care. In addition, the proportion of patients with shared care was higher $(90 \%)$ in our study population compared with two previous studies $(66 \%$ and $62 \%){ }^{25,26}$ The difference may be due to the fact that these two studies used patient-reported data with different demographic and cancer populations. Prior studies have not focused on racial/ethnic minorities, while this study focused on Black women who have a higher prevalence of comorbidities at breast cancer diagnosis.

We also did not find "cancer exceptionalism," a belief that once the primary care provider refers the patient to oncology, the oncologist will assume all non-cancer care and the cancer diagnosis will supersede all other health problems. ${ }^{55,}{ }^{56}$ Most patients were engaged with primary care following the breast cancer diagnosis, and their cancer specialists did not assume comorbid care. Primary care providers were managing most of the clinical care for diabetes and hypertension post-diagnosis. This finding is not unexpected since patients often have a longer relationship with their primary care provider than with their new cancer specialists, and primary care providers see themselves playing an important role in managing comorbidities during cancer treatment. ${ }^{57}$ Over two-thirds of primary care providers have reported to actively participate during cancer treatment, while almost a third of oncologists reported to actively manage comorbidities. ${ }^{58}$ Another survey across five hospitals found that $88 \%$ of primary care providers report being involved in care at the time of cancer diagnosis, and $44 \%$ report involvement during active treatment. ${ }^{59}$

We did not find an increase in the proportion of patients seeing a medical specialist following the breast cancer diagnosis compared with the 12 months before diagnosis, though involving specialist care for comorbidities after cancer diagnosis may be warranted. Retrospective studies of chart reviews found that diabetes care at an endocrinology clinic was superior at delivering quality diabetes care than at primary care clinics. ${ }^{60,61}$ Also, a referral to a cardiologist to assess and monitor the risk for cardiotoxicity may have been necessary for this patient population. The 2019 American College of Cardiology/American Heart Association Task Force guidelines for the prevention of cardiovascular disease explicitly state that "a team-based care approach is recommended for the control of risk factors associated with atherosclerotic cardiovascular disease." 45 The women in this study are already at increased risk for cardiovascular disease given their comorbidities and the prevalent risk factors such as obesity and older age. In addition, breast cancer treatment, including radiation, anthracycline, and other chemotherapy agents (e.g., trastuzumab), may place these women at additional risk for cardiovascular disease. ${ }^{62}$ Although the area of cardiooncology is growing, evidence-based guidelines with a shared care approach are missing and should include risk-stratified guidelines to screen and monitor women for cardiotoxicity during treatment and into survivorship. ${ }^{63}$

The strength of this study, which contributes to its generalizability, is that it is a population-based, prospective cohort of Black breast cancer survivors covering over 300 healthcare providers across over 200 health care settings in ten New Jersey counties. In a previous publication, we showed that the distribution of tumor stage and grade among participants in the cohort was similar to all eligible cases identified by the New Jersey State Cancer Registry in the same counties. ${ }^{33}$ We also abstracted medical and pharmacy records instead of relying solely on patient-reported data. We used the All-or-None approach to construct the optimal management measure, which looks at the entire sequence of care and not solely the parts, thereby encouraging a "system-of-care perspective." 48 However, some limitations should be noted. The small sample size limits the study's power. The study sample included patients with DCIS. However, because analyses were adjusted for stage, inclusion of DCIS cases should not have affected our conclusions. Medical records were abstracted in a standardized method, but providers' document medical visits differently, which may have led to misclassified outcomes. However, we chose measures based on longstanding, nationally recognized quality indicators used by employee-based health insurance companies, and Medicare and Medicaid programs for both reimbursement and quality monitoring. Additionally, this study only examined how health professionals managed comorbidities during cancer care and did not consider patients' preferences. This warrants further analyses from the patients' perspective to explore reasons for not seeking care or the ability to access care with a primary care provider or medical specialists. Lastly, there is no agreed-upon definition of shared care. We considered shared care when the patient had at least one visit with a primary care provider or medical specialist regardless of the medical visit's purpose within 12 months of cancer diagnosis. Studies are needed to validate how shared care has been defined and operationalized in the literature. 
In conclusion, most women in our study are engaged with shared care, and comorbid care by primary care providers continues even after the breast cancer diagnosis. Shared care was statistically associated with optimal management of diabetes and hypertension. Yet, $46 \%$ of patients experienced suboptimal comorbidity management. There may be missed opportunities for the delivery of high-quality comorbid care and cancer care when patients are not engaged with primary care and/or with medical specialists. These findings are important in that shared care may promote optimal clinical care management and clinical outcomes of diabetes and hypertension especially for Black women who disproportionately bear the burden of these comorbidities. However, we did not examine if there was a formal delineation of providers' roles or duplication of services. Future research is needed to explore the processes of shared care to determine whether medical providers are performing clinical care independently or via teamwork in which providers are communicating and coordinating care interdependently $[64,65]$.

Acknowledgments: We want to acknowledge the dedication and contributions of the staff at Rutgers Cancer Institute of New Jersey, Rutgers School of Public Health, New Jersey State Cancer Registry, and Roswell Park Comprehensive Cancer Center. We also want to thank all the women who agreed to participate in the Women's Circle of Health Follow-up Study and all the medical providers who helped us obtain medical records.

Corresponding Author: Michelle Doose, PhD, MPH; Healthcare Delivery Research Program, Division of Cancer Control and Population Sciences, National Cancer Institute, 9609 Medical Center Drive, 3E502, Rockville, MD 20850, USA (e-mail: michelle.doose@nih.gov).

Funding This work was supported by the National Cancer Institute of the National Institutes of Health (grant numbers R01CA185623, RO1CA133264, RO1 CA100598, PO1 CA151135, K22 CA138563, P30CA072720, and P30 CA016056); the American Cancer Society (RSGT-07-291-01-CPHPS); the Susan G. Komen Breast Cancer Foundation (POP131006); the US Army Medical Research and Material Command (DAMD-17-01-1-0334); the Breast Cancer Research Foundation (Ambrosone, Hong); a gift from the Philip L Hubbell family; and a gift from the Buckingham Foundation. Michelle Doose received support for this project provided by the Health Policy Research Scholars Program, a program supported by the Robert Wood Johnson Foundation. In addition, the New Jersey State Cancer Registry, Cancer Epidemiology Services, New Jersey Department of Health, is funded by the Surveillance, Epidemiology, and End Results (SEER) Program of the National Cancer Institute under contract HHSN261201300021I and control no. NO1-PC2013-00021, the National Program of Cancer Registries (NPCR), Centers for Disease Control and Prevention under grant NU5U58DP006279-02-00, and the State of New Jersey and the Rutgers Cancer Institute of New Jersey.

\section{Compliance with Ethical Standards:}

This study was approved by the institutional review boards of all participating institutions and written informed consent was obtained from all study participants.

Conflict of Interest: The authors declare that they do not have a conflict of interest.

Disclaimer: The content is solely the responsibility of the authors and does not necessarily represent the official views of the NIH.

\section{REFERENCES}

1. Siegel RL, Miller KD, Jemal A. Cancer statistics. CA Cancer J Clin. 2019;69(1):7-34. doi:https://doi.org/10.3322/caac.21551

2. Edwards BK, Noone A-M, Mariotto AB, Simard EP, Boscoe FP, Henley SJ, et al. Annual report to the nation on the status of cancer, 1975-2010, featuring prevalence of comorbidity and impact on survival among persons with lung, colorectal, breast or prostate cancer. Cancer. 2014;120(9):1290-314. doi:https://doi.org/10.1002/cncr.28509

3. American Cancer Society. Cancer facts \& figures 2020. Atlanta:American Cancer Society 2020.

4. Tammemagi C, Nerenz D, Neslund-Dudas C, Feldkamp C, Nathanson D. Comorbidity and survival disparities among black and white patients with breast cancer. JAMA. 2005;294(14):1765-72. doi:https://doi.org/ 10.1001/jama.294.14.1765

5. Boyle $\mathbf{P}$, Boniol M, Koechlin A, Robertson C, Valentini F, Coppens K, et al. Diabetes and breast cancer risk: A meta-analysis. Br J Cancer. 2012;107(9):1608-17. doi:https://doi.org/10.1038/bjc.2012.414

6. Lipscombe LL, Fischer HD, Austin PC, Fu L, Jaakkimainen RL, Ginsburg $\mathbf{O}$, et al. The association between diabetes and breast cancer stage at diagnosis: A population-based study. Breast Cancer Res Treat. 2015;150(3):613-20. doi:https://doi.org/10.1007/s10549-015-3323-5

7. Han H, Guo W, Shi W, Yu Y, Zhang $\mathbf{Y}$, Ye $\mathbf{X}$, et al. Hypertension and breast cancer risk: A systematic review and meta-analysis. Scientific Reports. 2017;7:44877. doi:https://doi.org/10.1038/srep44877

8. Centers for Disease Control and Prevention. National diabetes statistics report, 2017: Estimates of diabetes and its burden in the United States. U.S. Department of Health and Human Services, Atlanta, GA. 2017 https://www.cdc.gov/diabetes/data/statistics/statistics-report.html. Accessed March 25, 2020.

9. Fryar C, Ostchega Y, Hales C, Zhang G, Kruszon-Moran D. Hypertension prevalence and control among adults: United States, 2015-2016. Centers for Disease Control and Prevention, National Center for Health Statistics 2017. https://www.cdc.gov/nchs/data/databriefs/db289.pdf. Accessed March 25, 2020.

10. Sarfati D, Koczwara B, Jackson C. The impact of comorbidity on cancer and its treatment. CA Cancer J Clin. 2016;66(4):337-50. doi:https://doi. org/10.3322/caac.21342

11. Hong C-C, Ambrosone CB, Goodwin PJ. Comorbidities and their management: potential impact on breast cancer outcomes. In: Ganz PA, editor. Improving Outcomes for Breast Cancer Survivors: Perspectives on Research Challenges and Opportunities: Springer International Publishing, New York City; 2015. p. 155-75.

12. Pettit S, Cresta E, Winkley K, Purssell E, Armes J. Glycaemic control in people with type 2 diabetes mellitus during and after cancer treatment: A systematic review and meta-analysis. PLoS One. 2017;12(5):e0176941. doi:https://doi.org/10.1371/journal.pone.0176941

13. Srokowski TP, Fang S, Hortobagyi GN, Giordano SH. Impact of diabetes mellitus on complications and outcomes of adjuvant chemotherapy in older patients with breast cancer. J Clin Oncol. 2009;27(13):2170-6. doi:https://doi.org/10.1200/JCO.2008.17.5935

14. Barone BB, Yeh $\mathbf{H}$, Snyder $\mathbf{C F}$, et al. Long-term all-cause mortality in cancer patients with preexisting diabetes mellitus: A systematic review and meta-analysis. JAMA. 2008;300(23):2754-64. doi:https://doi.org/ 10.1001/jama.2008.824

15. Hershey DS, Given B, Given C, Von Eye A, You M. Diabetes and cancer: impact on health-related quality of life. Oncol Nurs Forum. 2012;39(5):449-57. doi:https://doi.org/10.1188/12.Onf.449-457

16. Braithwaite D, Tammemagi CM, Moore DH, Ozanne EM, Hiatt RA, Belkora $\mathbf{J}$, et al. Hypertension is an independent predictor of survival disparity between African-American and white breast cancer patients. Int J Cancer. 2009;124(5):1213-9. doi:https://doi.org/10.1002/ijc.24054

17. Berglund A, Wigertz A, Adolfsson J, Ahlgren J, Fornander $\mathbf{T}$, Warnberg $\mathbf{F}$, et al. Impact of comorbidity on management and mortality in women diagnosed with breast cancer. Breast Cancer Res Treat. 2012;135(1):281-9. doi:https://doi.org/10.1007/s10549-012-2176-4

18. Luo J, Virnig B, Hendryx M, Wen S, Chelebowski R, Chen C, et al. Diabetes, diabetes treatment and breast cancer prognosis. Breast Cancer Res Treat. 2014;148(1):153-62. doi:https://doi.org/10.1007/s10549014-3146-9

19. Afifi AM, Saad AM, Al-Husseini MJ, Elmehrath AO, Northfelt DW, Sonbol MB. Causes of death after breast cancer diagnosis: A US population-based analysis. Cancer. 2019. doi:https://doi.org/10.1002/ cncr.32648

20. Johnson CE, Saunders CM, Phillips M, Emery JD, Nowak AK, Overheu K, et al. Randomized controlled trial of shared care for patients 
with cancer involving general practitioners and cancer specialists. J Oncol Pract. 2015;11(5):349-55. doi:https://doi.org/10.1200/JOP.2014. 001569

21. Taplin SH, Weaver S, Salas E, Chollette V, Edwards HM, Bruinooge SS, et al. Reviewing cancer care team effectiveness. J Oncol Pract. 2015;11(3):239-46. doi:https://doi.org/10.1200/JOP.2014.003350

22. Shaw J, Sethi S, Vaccaro $\mathbf{L}$, Beatty $\mathbf{L}$, Kirsten $\mathbf{L}$, Kissane $\mathbf{D}$, et al. Is care really shared? A systematic review of collaborative care (shared care) interventions for adult cancer patients with depression. BMC Health Serv Res. 2019;19(1):120. doi:https://doi.org/10.1186/s12913-019-3946-Z

23. Churilla TM, Egleston BL, Murphy CT, Sigurdson ER, Hayes SB, Goldstein LJ, et al. Patterns of multidisciplinary care in the management of non-metastatic invasive breast cancer in the United States Medicare patient. Breast Cancer Res Treat. 2016;160(1):153-62. doi:https://doi. org/10.1007/s10549-016-3982-x

24. Zhao Y, Brettle A, Qiu L. The Effectiveness of Shared Care in Cancer Survivors-A Systematic Review. Int J Integr Care. 2018;18(4):2 doi:https://doi.org/10.5334/ijic.3954

25. Wallner LP, Abrahamse P, Uppal JK, Friese CR, Hamilton AS, Ward $\mathbf{K C}$, et al. Involvement of primary care physicians in the decision making and care of patients with breast cancer. J Clin Oncol. 2016;34(33):396975. doi:https://doi.org/10.1200/jco.2016.67.8896

26. Doose M, McGee-Avila J, Stroup AM, Ferrante J, Xu B, Herman NL et al. Shared care during breast and colorectal cancer treatment: is it associated with patient-reported care quality? J Healthc Qual. 2019 doi:https://doi.org/10.1097/jhq.0000000000000192

27. Jack B, Hillier V, Williams A, Oldham J. Hospital based palliative care teams improve the symptoms of cancer patients. Palliat Med. 2003;17(6):498-502. doi:https://doi.org/10.1191/0269216303pm794oa

28. Bosch M, Faber MJ, Cruijsberg J, Voerman GE, Leatherman S, Grol $\mathbf{R P}$, et al. Review article: Effectiveness of patient care teams and the role of clinical expertise and coordination: A literature review. Med Care Res Rev. 2009;66(6 Suppl):5s-35s. doi:https://doi.org/10.1177/ 1077558709343295

29. Institute of Medicine. Ensuring Quality Cancer Care. Hewitt M, Simone JV, editors. Washington, DC: The National Academies Press; 1999

30. Institute of Medicine National Research Council. From Cancer Patient to Cancer Survivor: Lost in Transition. Hewitt M, Greenfield S, Stovall E, editors. Washington, DC: The National Academies Press; 2006.

31. Commission on Cancer, American College of Surgeons. Cancer program standards 2012: Ensuring patient-centered care. 2012. https://www. facs.org/ /media/files / quality\%20programs /cancer/coc/ programstandards2012.ashx. Accessed March 25, 2020

32. ASCO-ESMO consensus statement on quality cancer care. Ann Oncol. 2006; 17 (7):1063-4. doi:https://doi.org/10.1093/annonc/mdl152

33. Bandera EV, Demissie K, Gin B, Llanos AAM, Lin Y, Xu B, et al. The Women's Circle of Health Follow-up Study: a population-based longitudinal study of Black breast cancer survivors in New Jersey. J Cancer Surviv. 2020. doi:https://doi.org/10.1007/s11764-019-00849-8

34. Rutgers Cancer Insitute of New Jersey. Epidemiology services - services. 2018. http://www.cinj.org/research/epidemiology-services-services. Accessed December 1, 2019.

35. Fleming BB, Greenfield S, Engelgau MM, Pogach LM, Clauser SB, Parrott MA. The Diabetes Quality Improvement Project: Moving science into health policy to gain an edge on the diabetes epidemic. Diabetes Care. 2001;24(10):1815-20. doi:https://doi.org/10.2337/diacare.24.10. 1815

36. National Committee for Quality Assurance. HEDIS 2018. 2018. http:// www.ncqa.org / Portals / 0 / HEDIS Q M / HED IS 2018 HEDIS\%202018\%20Measures.pdf?ver=2017-06-28-134644-370. Accessed May 19, 2018.

37. The TRIAD Study Group. Health systems, patients factors, and quality of care for diabetes. Diabetes Care. 2010;33(4):940.

38. American Diabetes Association. 6. Glycemic targets: standards of medical care in diabetes-2018. Diabetes Care. 2018;41(Suppl 1):S55-S64 doi:https://doi.org/10.2337/dc18-S006

39. National Committee for Quality Assurance. Diabetes Recognition Program. 2018. http://www.ncqa.org/programs/recognition/clinicians/diabetes-recognition-program-drp. Accessed March 08, 2018.

40. National Committee for Quality Assurance. Disease management performance measures. 2018. http://www.ncqa.org/programs/accreditation/ disease-management-dm/dm-performance-measures. Accessed March 9, 2018 .

41. Centers for Medicare and Medicaid Services. Core Measures: ACO and PCMH/ Primary Care Measures. 2017. https://www.cms.gov/Medicare/
Quality-Initiatives-Patient-Assessment-Instruments/QualityMeasures/ Downloads/ACO-and-PCMH-Primary-Care-Measures.pdf.

42. Saaddine JB, Cadwell B, Gregg EW, et al. Improvements in diabetes processes of care and intermediate outcomes: United States, 1988-2002. Ann Med. 2006;144(7):465-74. doi:https://doi.org/10.7326/0003-4819144-7-200604040-00005

43. James PA, Oparil S, Carter BL, et al. 2014 evidence-based guideline for the management of high blood pressure in adults: report from the panel members appointed to the eighth Joint National Committee. JAMA. 2014;311(5):507-20. doi:https://doi.org/10.1001/jama.2013.284427

44. U.S. Department of Health and Human Services, National Institute of Health, National Heart Lung and Blood Institute. The seventh report of the Joint National Committee on prevention, detection, evaluation, and treatment of high blood pressure. Bethesda, MD: National Heart, Lung , and Blood Institute2004.

45. Arnett DK, Blumenthal RS, Albert MA, Buroker AB, Goldberger ZD, Hahn EJ, et al. 2019 ACC/AHA guideline on the primary prevention of cardiovascular disease. Circulation. 2019:Cir0000000000000678. doi:https://doi.org/10.1161/cir.0000000000000678

46. Siu AL. Screening for high blood pressure in adults: U.S. Preventive Services Task Force recommendation statement. Ann Intern Med 2015;163(10):778-86. doi:https://doi.org/10.7326/m15-2223

47. Anderson TJ, Gregoire J, Hegele RA, Couture P, Mancini GB, McPherson R, et al. 2012 update of the Canadian Cardiovascular Society guidelines for the diagnosis and treatment of dyslipidemia for the prevention of cardiovascular disease in the adult. Can J Cardiol. 2013;29(2):151-67. doi:https://doi.org/10.1016/j.cjca.2012.11.032

48. Nolan T, Berwick DM. All-or-none measurement raises the bar on performance. JAMA. 2006;295(10):1168-70. doi:https://doi.org/10. 1001/jama.295.10.1168

49. Andersen RM. Revisiting the behavioral model and access to medical care: does it matter? J Health Soc Behav. 1995;36(1):1-10.

50. Taplin SH, Anhang Price R, Edwards HM, Foster MK, Breslau ES, Chollette V, et al. Introduction: Understanding and influencing multilevel factors across the cancer care continuum. J Natl Cancer Inst Monogr. 2012;2012(44):2-10. doi:https://doi.org/10.1093/ jncimonographs/lgs008

51. Zapka JG, Taplin SH, Solberg LI, Manos MM. A framework for improving the quality of cancer care. Cancer Epidemiol Biomarkers Prev. $2003 ; 12(1): 4$.

52. Donabedian A. Evaluating the quality of medical care. Milbank Mem Fund Q. 1966;44(3 Suppl):166-206.

53. Zou G. A modified poisson regression approach to prospective studies with binary data. Am J Epidemiol. 2004;159(7):702-6.

54. Institute of Medicine. In: Smedley BD, Stith AY, Nelson AR, editors. Unequal Treatment: Confronting Racial and Ethnic Disparities in Health Care. Washington (DC): National Academies Press; 2003.

55. Rubinstein EB, Miller WL, Hudson Sv, Howard J, O'Malley D, Tsui J, et al. Cancer survivorship care in advanced primary care practices: a qualitative study of challenges and opportunities. JAMA Intern Med 2017;177(12):1726-32. doi:https://doi.org/10.1001/jamainternmed. 2017.4747

56. Weiner J. Precision medicine meets cancer exceptionalism. Health PolicySense. 2017. https://ldi.upenn.edu/healthpolicysense/precisionmedicine-meets-cancer-exceptionalism. Accessed October 31, 2019.

57. Del Giudice ME, Grunfeld E, Harvey BJ, Piliotis E, Verma S. Primary care physicians' views of routine follow-up care of cancer survivors. J Clin Oncol. 2009;27(20):3338-45. doi:https://doi.org/10.1200/jco.2008.20. 4883

58. Klabunde CN, Ambs A, Keating NL, He Y, Doucette WR, Tisnado D, et al. The role of primary care physicians in cancer care. J Gen Intern Med. 2009;24(9):1029-36. doi:https://doi.org/10.1007/s11606-0091058-x

59. Aubin M, Vézina L, Verreault R, Fillion L, Hudon E, Lehmann F, et al Patient, primary care physician and specialist expectations of primary care physician involvement in cancer care. J Gen Intern Med. 2012;27(1):8-15. doi:https://doi.org/10.1007/s11606-011-1777-7

60. Leinung MC, Gianoukakis AG, Lee DW, Jeronis SL, Desemone J. Comparison of diabetes care provided by an endocrinology clinic and a primary-care clinic. Endocr Pract. 2000;6(5):361-6. doi:https://doi.org/ 10.4158/ep.6.5.361

61. Ho M, Marger M, Beart J, Yip I, Shekelle P. Is the quality of diabetes care better in a diabetes clinic or in a general medicine clinic? Diabetes Care. 1997;20(4):472-5.

62. Mehta LS, Watson KE, Barac A, Beckie TM, Bittner V, Cruz-Flores S, et al. Cardiovascular disease and breast cancer: where these entities 
intersect: A scientific statement from the American Heart Association. Circulation. 2018;137(8):e30-e66. doi:https://doi.org/10.1161/cir. 0000000000000556

63. Xie Y, Collins WJ, Audeh MW, Shiao SL, Gottlieb RA, Goodman MT et al. Breast cancer survivorship and cardiovascular disease: emerging approaches in cardio-oncology. Curr Treat Options Cardiovasc Med. 2015;17(12):60. doi:https://doi.org/10.1007/s11936-015-0421-y

64. Taplin SH, Weaver S, Chollette V, Marks LB, Jacobs A, Schiff G, et al. Teams and teamwork during a cancer diagnosis: interdependency within and between teams. J Oncol Pract. 2015;11(3):231-8. doi:https://doi. org/10.1200/jop.2014.003376
65. Kosty MP, Bruinooge SS, Cox JV. Intentional approach to team-based oncology care: Evidence-based teamwork to improve collaboration and patient engagement. J Oncol Pract. 2015;11(3):247-8. doi:https://doi. org/10.1200/JOP.2015.005058

Publisher's Note: Springer Nature remains neutral with regard to jurisdictional claims in published maps and institutional affiliations. 